\title{
A study of STEM education's integration in vocational school teacher's instruction guidelines
}

\author{
Suebpong Prabyai ${ }^{1, *}$, Khukrit Silalaiy ${ }^{1}$ \\ ${ }^{1}$ Ramkhamhaeng University, Bangkok, Thailand
}

\begin{abstract}
This research aims to (1) study the problems with integrating Science, Technology, Engineering and Mathematics (STEM) education into teaching by vocational college teachers and (2) to determine the most appropriate method for applying STEM education to teaching by vocational college teachers. The sample for this study was 400 vocational college teachers affiliated with the Office of the Vocational Education Commission, Bangkok, chosen using the technique of simple random sampling. The research instruments included a questionnaire on the problems with integrating STEM education into teaching by vocational college teachers and the demands of such integration, with a reliability of .945. The statistical methods included mean, standard deviation, and content analyses of focus group discussions. The results showed that (1) the problems with integrating STEM education into teaching by vocational college teachers related to four aspects: content, operational skills, learning activities, and an application of practical knowledge at high levels and (2) the most appropriate method of applying STEM education to teaching by vocational college teachers should include encouraging teachers to incorporate lesson content of STEM education which allows the learners to think reasonably and logically, while improving their ability to seek knowledge and solve problems systematically. Teaching and learning activities should also focus on 21st century skills and how to integrate those skills into knowledge gained from STEM education so that it benefits society in practical ways.
\end{abstract}

\section{Introduction}

Due to the fast-changing world and the technological advancement of communication, there has been a phenomenon of massive use of information available in different sources and competition for economic and business advantages. Every country rapidly improved their population's quality to be able to thrive and compete in the labor market with other countries. Education was, therefore, adjusted to integrate the learning of science, technology, mathematics, and engineering processes so that students can apply such knowledge to real-life problems and solutions and to their careers in the future. Teachers

\footnotetext{
* Corresponding author: suebpong_p@hotmail.com
} 
and students needed to adjust to acquire necessary skills as a teacher and student of the 21 st century.

An educational model which has integrated the knowledge of science, technology, engineering and mathematics or Science Technology Engineering and Mathematics Education (STEM), known as 'STEM education', was designed to strengthen education. An integration of STEM education to classroom learning and the application of STEM education to practical activities in a classroom could be achieved with the integration of content, laboratory skills, learning activities and/or practical knowledge application. Such integration could be done with each subject or combination of different subjects. The application of STEM education consists of intradisciplinary, multidisciplinary and interdisciplinary learning integration. These would help the students understand the relationships among science, technology, engineering, and mathematics subjects. For multidisciplinary learning integration, instructors of STEM education collaborated to design learning activities to which students could apply their knowledge and skills from four subjects, which were science, technology, engineering, and mathematics [1]. Occupations, which were related to science, technology, engineering, and mathematicssuch as engineers, physicians, scientists etc., are important drivers of the country's development both economically and socially. However, quality workers were still not enough [2].

The number of workforces in the field of science, technology, engineering, and mathematics in the 20th century was in a downward trend. There were fewer high school graduates who were interested in the faculties related to such fields. The current lower learning outcomes of basic education when compared to the past reflected the problems of the quality of science, technology, and mathematics learning management in schools. The promotion of such fields to be related to real lives would lead to students' eagerness to study. Their analytical and problem-solving skills would also be improved together with other skills related to systematic thinking. These would be useful for their future career and the country's economic development.

STEM is an abbreviation of four subjects, which are science, technology, engineering, and mathematics, and refer to the connectedness of knowledge from these subjects [3]. STEM is a reference to an occupational group related to science, technology, engineering, and mathematics. STEM education was an instructional guideline integrating four interdisciplinary subjects, which were science, technology, engineering, and mathematics, with emphasis on real-life problem-solving skill and the development of new processes or outcomes to be useful in lives and work. STEM education helped students build connections between different disciplines, and real lives and work.

Theoretical understanding was established through practical exercises where students learned to pose questions, solve problems, research, analyze new discoveries, and apply such discoveries to real-life situations. Such connections between different disciplines and real lives would help students understand the relationship among science, technology, engineering, mathematics, social science, and humanities.

The world changed rapidly with technological advancement of communication, and this led to a phenomenon of massive use of information, which was available through different sources, and a phenomenon of competition for economic and business advantages. Every country speedily improved their population's quality to be able to thrive and compete in the labor market with other countries. As a result, education was adjusted to integrate the learning of science, technology, mathematics, and engineering processes so that students can apply such knowledge to real-life problems and solutions and to their career in the future. Teachers and students needed to adjust themselves to acquire necessary skills as a teacher and student of the 21 st century. Thailand showed such integration through science projects in the basic education level and work-integrated learning (WIL) of vocational and university education. Concepts of these two activities resembled those of STEM education. 
However, such integrated learning processes were in small numbers. STEM education was, therefore, encouraged focusing on the use of STEM for learning or working. The students' technology, engineering, science, and mathematics skills still needed further improvement. Every level of operation needed the application of STEM, and STEM education was also related to becoming a world leader in science and to economic growth.

Educators divided STEM education into eight-step learning units which were to (1)select central standards, (2)align daily life problems, (3)select supplemental standards to support central standards, (4) instruct STEM standards, (5) engage student participation, (6) troubleshoot the designs, (7) evaluate the designs, and check and give scores after the adjustment from step 6 , and (8) present completed projects[4].

\section{Methodology}

\subsection{Population and sample group}

The present study was a mixed-method research. The population was 3,640 instructors of vocational schools under the Office of the Vocational Education Commission, Bangkok. The simple random sampling method was used. Based on the Krejcie and Morgan's [5] formula, the appropriate number for the sample group of this study should be 351 . The sample group of the present study consisted of 351 instructors and nine informants.

The instrument used was a questionnaire designed by the researcher. In the design process, the content validity of each question was conducted using the Index of Item Object Congruence (IOC) with an acceptable reliability coefficient of 0.6-1.00. The questionnaire was tried out with 30 instructors of vocational schools who were not in the sample group. The data were then analyzed with a statistical program for Cronbach's alpha coefficient and the results of reliability coefficient was 0.945 .

\subsection{Data analysis}

From the study of problems and needs of vocational school teachers in integrating STEM education to their instruction, a preliminary analysis was conducted for basic statistical calculation. Frequency distributions, percentages, means, and standard deviations were calculated. Data were collected with a five-rating scale, which were very high, high, moderate, low, and very low.

\section{Results and discussions}

For the present study, the participants were asked about their personal information, which were gender and levels of education. The results showed that most vocational school teachers were male, and were more than 40 years old, which accounted for 65 and 57 percent, respectively.

Teachers who graduated with a master's degree accounted for 58.2 per cent, those who had more than 15 years of experience accounted for 64.2 per cent, those who taught the vocational certificate level accounted for 52.5 percent, and those who taught the high vocational certificate level accounted for 28.5 percent. 


\subsection{Results of problems in the integration of STEM education in vocational school teachers' instruction}

The data of the present study were collected through the questionnaire asking about problems in the integration of STEM education to classroom learning by vocational school teachers. The results are shown in Table 1.

Table 1. Means, standard deviations, and degrees of each aspect of problems for vocational school teachers.

\begin{tabular}{|c|c|c|c|}
\hline Learning management & $\bar{x}$ & SD & Degree \\
\hline 1. Content & 3.92 & .745 & high \\
\hline 2. Laboratory skills & 3.88 & .780 & high \\
\hline 3. Learning activities & 3.92 & .756 & high \\
\hline 4. Practical knowledge application & 3.90 & .766 & high \\
\hline Total & 3.903 & .757 & high \\
\hline
\end{tabular}

As presented in Table 1, the overall results of the problems of the integration of STEM education in vocational school teachers' instruction were at high level ( $\overline{\boldsymbol{x}}=3.9033)$. The

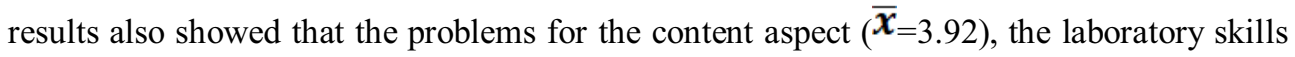

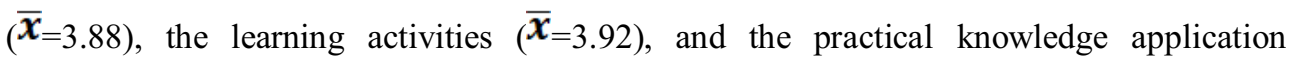
$\left(\overline{\boldsymbol{x}}_{=3.90) \text { were at high levels. }}\right.$

The data from the study of the integration of STEM education in vocational school teachers' instruction indicated that the overall results of each problem were at a high level, as concluded and discussed below.

1. For the content, it was found that the problems of STEM education's integration in vocational school teachers' instruction were related to the needs of the teachers to have thorough knowledge and understanding of science subjects, which were applicable to STEM education. Their abilities to analyze, rationalize, and apply mathematical concepts to explain and predict phenomena of different contexts were also needed. In addition, they should be able to connect different subjects related to STEM education, and understand the development or the acquisition of technology by applying STEM education to an engineering design process to design a tool or means to improve quality of life. Skills which supported students' logical thinking process needed to be promoted.

They also needed to understand the role of mathematics in management, be accessible to technology, have scientificlaboratory skills, understand the role of mathematics in diagnosis and decision making, make decision based on information and verified evidence, research, and systematically solve a problem. These were in line with [6] which reported that instructors had to play a role in learning management, encourage students to have logical thinking processes, and emphasize the integration of STEM education (science, technology, engineering and mathematics) by promoting learning through surveying for further information and providing experience of problem solving. [7]

2. For the laboratory skills, the problems of STEM education's integration in vocational school teacher's instruction were that the instructors needed to have the skills to teach information technology, thinking, scientific, mathematics, life, problem solving and communication skills with integration to STEM education. This was in accordance with [8] which mentioned the importance of technology and that the instructors realized the necessity of educating themselves about the integration of STEM education.

3. For learning management, the problems of STEM education's integration in vocational school teacher's instruction were related to theneeds to apply STEM education to real life situations. STEM education activities outside the classroom which aimed for the students' learning achievement were needed. STEM education should be included in 
classroom learning by being listed as an elective subject in elective subject groups, and incorporated STEM activities to related content of each subject. This supported the study of [9] which showed that STEM education focused on learning management of an institution, encouraging participation, and creating appropriate learning environment.

4. For the practical knowledge application, the problems of STEM education's integration in vocational school teachers' instruction were related to their needs to pass on the knowledge of science which the students could practically apply to real life situations. In addition, the teachers needed to teach STEM education for social skills, and teach technology, mathematics, and engineering for practical use.

\subsection{Results of the study of STEM education vocational school teacher's instruction}

The results of STEM education's integration in vocational school teacher's instruction guidelines were concluded and discussed as follows.

1. For the content, knowledge and understanding of content in the science subject which could be integrated to STEM education and the ability to relate the content of such subject and STEM education should be developed. This could be achieved by focusing on the students' logical thinking process, and the development of their research and systematic problem-solving skills. Decision making based on information and verified evidence was encouraged with emphasis on analysis with reasoning and mathematical application to explain and predict different phenomena under different contexts.

This was in line with the studies of [10] and [11] which found that STEM education significantly improved the students' problem solving and critical thinking skills. Furthermore, an understanding of the role of mathematics for diagnosis and decision making was encouraged together with its role for operation and access to technology. Knowledge for developing and accessing technology by integrating STEM education with engineering design process should be improved to construct a tool or means to improve quality of life. For STEM education's integration in vocational school teacher's instruction guidelines, the content should be ranked into three levels.

The first one was the primary level, whose focus was on general content, followed by the intermediate level, whose focus was on content which were applicable to daily lives, and the advanced level, whose learning management was conducted with community-based learning which would lead to a STEM learning community.

The advanced level should also focus on outcome-based education and content that was sustainably applicable to the students' future career. This supported [12] study which found that outcome-based education, curriculum design and activities needed to support the STEM learning community. Therefore, teaching materials which focused on project-based learning was a good option in STEM education especially students' creations in relation to social or environmental problems that could be shared through social media platforms to enhance the relationship between schools and society.

2. For the laboratory skills, an improvement of teachers' in terms of scientific methods to be used in classroom learning and teaching which could be integrated with STEM education was needed. Such integration could be done through different activities of existing subjects to promote mathematical skills. Activities supporting the teachers' thinking process for learning management with an integration of STEM education were also needed. In addition, information technology should be incorporated to STEM education along with activities to promote scientific processes, mathematical skills, and information technological skills of the teachers for outcome-based learning. This would improve the students' competencies which was in line with the research by [13]. It showed that STEM education increased students' self-confidence, and problem-solving and 
technological skills. It also helped students learn necessary skills to create innovations and technology withjudgments and reasons. The results supported [14] study which indicated that a course designed by a science teacher through multidisciplinary integration and with engineering design process was able to improve three-dimensional thinking, which consisted of creativity and scientific consideration, problem-solving, and imagination. STEM education also played a part in a society's scientific development and increased the development levels.

3. For the learning activities, the promotion of problem-solving, communication, and life skills which teachers could integrate with STEM education were needed along with learning activities to develop problem-solving, communication and life skills with an integration to STEM education. The skills in focus were those that were necessary for the 21 st century. A study by [15] found that people who were involved in technical and vocational education and training needed to prepare their students to be ready for life and work in the 21 st century. This preparation includedproviding sustainable knowledge and skills. Learning and teaching management should follow current educational concepts and practice (such as student-centered learning with real life situations in classrooms and learning environment). In addition, important skills for the 21 st century provided should be appropriate to students' levels. Each activity should also focus on improving students' apparent skills.

4. For the practical knowledge application, the development of skills to teach science, technology, engineering, and mathematics were needed and their focus should be on skills of the 21 st century. This would help teachers pass on and integrate these skills to STEM education that would lead to life skills and students' actionable application. Assessment, evaluation of different skills and thinking processes were done through; for example, rubrics or other forms of evaluations such as an assigned situation which aimed for the students to use their thinking processes and to apply STEM education to solve a problem through application, adaptation and implementation $[16,17,18,19]$.

\section{Conclusions}

From the study of STEM education's integration in vocational school teacher's instruction guidelines through a group interview, the results collected from the participants' opinions regarding each aspect were concluded as follows.

1. The problems of STEM education's integration in vocational school teacher's instruction in terms of the content, laboratory skills, learning management and practical knowledge application were at a high level overall.

2. STEM education's integration in vocational school teacher's instruction guidelines were concluded as follows:

2.1 The content of STEM education's integration in vocational school teacher's instruction should be arranged into three levels, which are primary knowledge level focusing on general knowledge, intermediate knowledge level focusing on content which could be used in daily lives, and advanced knowledge level focusing on community base learning, outcome base education, integration of STEM education with art or STEAM, and content which could be used for future careers for sustainable knowledge.

2.2 For the laboratory skills, the development of teachers' skills for scientific methods to be integrated with STEM education in their classes were needed. It should focus on students' outcomes to improve their competencies. Learning activities to promote mathematical skills were needed through different styles of teaching and with integration to STEM education. There should also be a promotion of learning and teaching activities to help the teachers manage the integration of STEM education with laboratory skills. Further 
development on skills related to scientific methods, on learning activities for mathematics and teachers' skills on information technology were also needed.

2.3 For the learning management, activities promoting problem-solving, communication, and life skills which could be integrated to STEM education should be promoted. These skills should focus on what were necessary in the 21 st century, and appropriate for the students' levels and their characteristics. Each activity needed to emphasize on students' apparent skills.

2.4 For the practical knowledge application, an improvement of skills to teach science, technology, engineering, and mathematics necessary for the 21 st century was needed. This would help teachers teach and integrate such skills with STEM education for real life application. As a result, the students would be able to put these skills into practice. The skills taught needed to be actionable and evaluated with rubrics or other types of assessment. One example was assigning a situation for students to use their problemsolving skills and use what they learned for STEM education to come up with a solution through application, adaptation, and implementation.

\section{Acknowledgement}

The researcher would like to express his gratitude to the Research and Development Institute of Ramkhamhaeng University for supporting the present study with the research fund of fiscal year 2018 .

\section{References}

1. A. Privara, Migration Letters 16(2), 245-254 (2019)

2. R. Bybee, The teaching of science: 21st-century perspectives (Arlington, VA. NSTA Press, 2013)

3. A Framework for K-12 Science Education: Practices Crosscutting Concept, and Core Ideas (Washington, DC, National Research Council, Division of Behavioral and Social Science and Education, 2012)

4. R. Amanda, Technology and Engineering Teacher 73(1), 22-27 (2013)

5. R.V. Krejcie, D.W. Morgan, Educational and Psychological measurement 30(3), 215226 (1970)

6. J.D. Basham, M.T. Marino, Teaching Exceptional Children 45(4), 8-15 (2013)

7. A. Asghar et al., Interdisciplinary J. of Problem-based Learning 6(2), 85-125 (2012)

8. H.H. Wang et al., J. of Pre-College Engineering Education Research 1(2), 1-13 (2011)

9. E. Niyazi, L.S. Carol, International J. of Education in Mathematics, Science and Technology 3(1), 77-92 (2015)

10. A. Cotabish et al., School Science and Mathematics 113(5), 215-226 (2013)

11. N. Abdullah, L. Halim, E. Zakaria, Eurasia J. of Mathematics, Science \& Technology Education 10(3), 165-174 (2014)

12. R.W. Bybee, The case for STEMe: Challenges and opportunities (National Science Teachers Association, 2013)

13. J. Morrison, TIES STEM education monograph series, attributes of STEM education (Baltimore. MD, TIES, 2006)

14. D. Ushakov et al., Espacios 40(34), 16-22 (2019)

15. E.M. Reeve, Asian International J. of Social Sciences 16(4), 65-82 (2016) 
16. L.S. Nadelson, A. Seifert, Teacher Education and Practice 26(2), 242-265 (2013)

17. J.A. Vasquez et al., STEM Lesson Essentials: Integrating Science,Technology, Engineering, and Mathematics (Portsmouth, NH. Heinemann, 2013)

18. A. Př́ivara, E. Rievajová, M.M. Yüceşahin, Migration Letters 16(4), 585-594 (2019)

19. M. Privarova, A. Privara, Inter. J. Of Environmental \& Science Education 11(18), 12909-12917 (2016) 